\title{
Understanding and balancing mixed-use schemes: The key to creating successful communities
}

Received (in revised form): 26 January 2004

Mark Anders

is managing director of international practice REID architecture's Birmingham office. Mark is one of the practice's retail specialists and has undertaken study tours in the USA, South Africa, Australia, the Far East, Europe and the UK. Mark has published many articles on retail design and has acted as an awards assessor for both the RIBA and the Royal Anniversary Trust.

\begin{abstract}
The right balance of uses within a scheme may make a mixeduse scheme successful and financially viable in its own right, but it is necessary to ensure that these types of development genuinely contribute to the sustainability of an area, and that they relate to their immediate setting and assist in the regeneration of the surrounding vicinity.

This paper will investigate how these types of scheme can and should be integrated into the street scene without creating monolithic developments that cannot be broken down into varieties of scale and form. It will consider the term 'mixed use' and dispel its simplistic definition. Mixed use can equally be a combination of single-sector uses and work just as effectively, as long as the wider picture is appreciated. These developments need to become more outward looking and create a sense of place. With finite space available the paper will also look at how existing developments, particularly traditional shopping centres, can be augmented and improved and how businesses themselves can assist in the regeneration process to benefit both themselves and the local population.
\end{abstract}

\section{Keywords:}

holistic approach, legibility, integration, appropriate scale, sense of place, flexibility, adaptability

\section{INTRODUCTION}

Positively encouraged by the government, mixed-use schemes are being championed as regeneration saviours. But there is a worrying tendency among over-keen developers and councils to take a generic and somewhat over-simplistic view of what mixed use actually means and constitutes. 


\section{The generic picture}

\section{The wider issue}

\section{The changing nature}

A traditional make-up involves retail, usually with some leisure, a combination seen as workable and reliable, together with either a mixture of residential units or an office element to complete the jigsaw, like the recently completed Rushes development in Loughborough, which is anchored by a large Big W store and complemented by other retail units, bars, a health and fitness club and 33 residential units. Pockets of almost identical developments are now springing up everywhere.

The other extreme is developments that incorporate about 90 per cent residential with a small element of other uses. These schemes are mainly developed by house builders, often without a grip on the wider context. The residential units are not designed with the inherent flexibility to change to offices or hotels should market forces require it, as opposed to commercial schemes at the other end of the spectrum where the ability to alter uses is an integral element. Is there a danger of creating social problems for the future?

It is necessary to look at the broader picture and consider how one scheme works with or against another in order to produce relationships that actually integrate with the city. There is no logic in trying to put hotels, residential units or offices in every scheme just because they stack the figures up. There is only going to be finite demand.

Most mixed-use schemes, or the potential for them, lie in brownfield sites in the less desirable parts of town centres. That is why local authorities proactively support their development. But there is still a problem with planners drawing up strategic plans without understanding the underlying demand for uses. It might be about creating the right mix of uses for an area rather than a simple, single block.

The nature of mixed use can and should change from the heart of the city to the periphery. Demographics, culture and locale all affect how different uses are able to integrate together. A hospital on the city fringes, maybe with associated businesses and offices, accommodation for nurses and their families and cafés and shops, equally fulfils the definition of 'mixed use' but has a very different feel to a town's central core.

The propensity to put everything into one bag without regard for the surrounding area or space has to be overcome and a more holistic approach to city regeneration adopted.

\section{UNDERSTANDING THE STREET SCENE: LEGIBILITY}

A particular issue that appears to be causing difficulty at the moment is the lack of understanding within schemes of how uses above street level come down and integrate into the street scene. How will the city block change throughout the day? There is a need to understand its nature. How does it relate to the civic space? Too often certain areas go dead due to the operational make-up retail-heavy areas that shut down at $6 \mathrm{pm}$, for example. How does 


\section{Learning from Europe}

one make the street more vibrant? It is not as easy as scattering a few bars and restaurants around. How does one manage traffic? Should pedestrian zones or shared traffic/pedestrian areas at certain times be created to generate a particular buzz? It is necessary to understand spaces in, around, between and at the back of buildings.

In Eastern Europe particularly, great thought is put into how private and semi-private spaces are linked through city blocks. While areas at the front are very public and open, with easy access, historically the inner block is bisected by pedestrian routes connecting private and semi-private spaces and thus a hierarchy is formed. With less activity at the back, 'pocket parks', with soft landscaping, are provided where people can relax and recuperate. In other quieter areas, more serviced-type offers may also be established, such as cafés and smaller, kiosk-style retail units. These spaces are used as secondary links from one main space to another.

The emphasis behind Potsdam Platz in Germany is about creating a quarter. Certain buildings have a mix of uses; others have a single use but they still contribute to the overall mix (Figure 1). What particularly draws this area together is the successful interconnections which are effectively used. The lower floors tend to be retail and leisure with integrated internal spaces and through routes, while the upper levels provide more semi-private uses and areas.

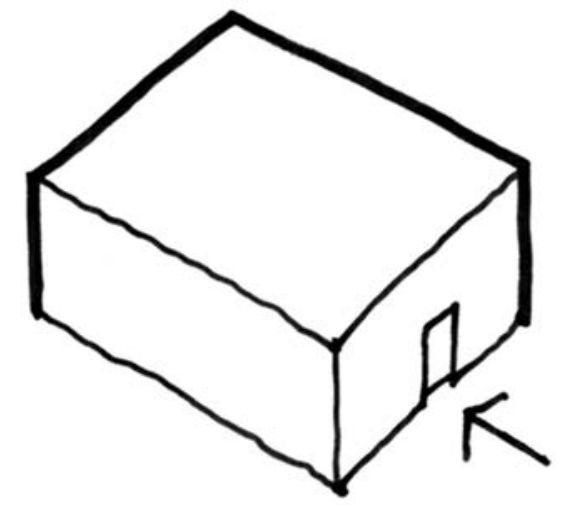

Figure 1: Stand-alone, single aspect unit

Scale is increasingly becoming an issue. By their nature, mixeduse schemes are large and complex affairs. People are finding it hard to convert the mass into a pedestrian, human scale and modify the architecture to deal with that. What one does not want to see with the development of mixed use, while the majority are outward looking, is the tendency for big monolithic buildings that cannot be broken down into varieties of scale and form (Figure 2). This occurred a lot with shopping centres during the mid-1980s and early 1990s. Developers were keen to ensure their scheme had its own feel and architectural style but often did this without relating the building to the squares and streets that it spilled out onto and without consideration for the buildings next to it. Proposals for 


\section{Respecting the surrounding environment}

\section{Creating a 'place'}

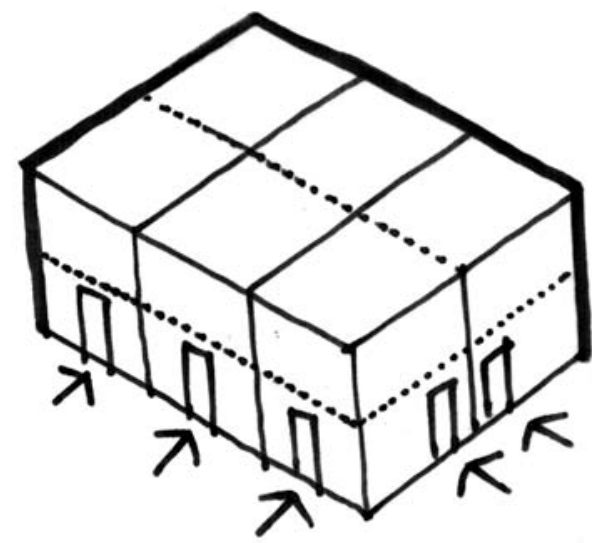

Figure 2: Basic mixed use

modern shopping centres, like Cardiff, Chester and Liverpool, are based upon open and covered streets and are trying to integrate into the urban fabric with different styles of architecture. While still large scale, they have responded well to the street-scene issue and local context. They react utilising the same mix as the traditional shopping centre, with an anchor department store, which in many cases is becoming an iconic building, a car park and smaller units, but rather than one huge mass the elements are broken down, knitting into the existing fabric. They have started to overcome the problem of trying to replicate the fine grain of details of existing streets and centres, which have developed naturally and historically over time, with a variety of uses and styles. Character is being retained and enhanced by the maintenance and incorporation of old, existing buildings, whereas the tendency before had been to demolish these.

Equally important is creating the right sense of place. The traditional shopping centre, in simple terms, is a series of shops around a collection of managed spaces. Although somewhat artificial, shopping centre management can control what happens in these areas. While this should happen with mixed-use schemes, within the street there is the difficulty of ownership. How can the appropriateness of the street scene be ensured? If it is not handled correctly, there is a danger of creating a series of big blocks that do not relate or create the right environment around them. In Europe many mixed-use developments work around a good public realm - thought is properly given to landscape features, creating the right lighting or the integration of cycle routes, for example. Environments are needed that allow everything to happen without being regimented, ordered and characterless.

Liverpool City Council is looking to privatise 35 public rights of way to enable Grosvenor's $£ 750 \mathrm{~m}$ redevelopment of the Paradise Street area. In North America there has been a drift towards the managed environment of shopping malls and the city centres have died. The Liverpool proposals aim to create a managed 


\section{Reducing blank frontages}

The Gate, Newcastle environment in the city centre so that this drift is avoided. These streets will be policed in a similar way to a conventional shopping centre, with people called quarter masters.

In the UK there is often a great problem with legibility, and development layouts are not always obvious for walking around and finding anything. They need a framework and appropriate linkages to pull all the various strands together. Many mixed-use schemes have elevations bustling with lots of activity but the rest are blank and lifeless, so in overall terms not actually contributing to the success of the city block. It is necessary to look at the implementation of level changes to the development's advantage, and the increased introduction of underground parking and servicing could be a solution for high-density schemes, thereby reducing blank frontages usually used for this purpose.

\section{SINGLE SECTOR: MIX OF TYPES}

The various strands can just as legitimately come from one sector and still constitute a mixed-use scheme. The Gate urban entertainment centre in Newcastle, which the author's company designed for Land Securities, provides a range and mix of leisure types (casino, cinema, late-night bars) set within the framework of the Grainger Town area to knit different elements of the city together.

In recent years developments have drawn people to the outer edges of Newcastle, so the challenge for the design team was to provide an imaginative entertainment venue that would breathe life back into an unused part of the city centre.

The Gate provides a transition point from retail to leisure. It connects to the Chinese-themed food area, which is linked to a variety of bars and restaurants popular with the office crowd and is on the route to Newcastle Football Club's St James' Park stadium, and links to the historic Blackfriars area, which in turn joins to the old Roman Walls. A very identifiable mix of uses is clustered around a predominantly residential area with the large scope of leisure uses working because they are all utilised at different times of the day and at different times of the week. It is this mass and identity that help the overall regeneration of the area.

This mass, however, is not sufficient for it to work in its own right. If the venue was located in the middle of a field it is unlikely anyone would go there. The Gate is of a sufficient uniqueness to create its own identity but it needs the adjacent framework to hang on. The scheme won Best Mixed Use Scheme at the 2003 Leisure Property Awards.

\section{OPENING UP THE TRADITIONAL SHOPPING CENTRE}

Another important option in adopting the principles of mixed use as a catalyst for regeneration is considering, using and enhancing what is already there. The traditional shopping centre, for example, offers opportunities that strangely do not seem to be exploited often enough. 


\section{Transport links}

\section{Alternative uses}

A key avenue to explore is opening up the centre so that it is no longer an enclosed building but instead integral to the urban fabric. Wayfinding is paramount in shopping centres so one should utilise this strength and ingrain these routes into the street scene in the tradition of old arcades and start knitting the city together. The use of external finishes on both new and historic routes is more evident in continental centres and there is no reason why this approach cannot be adopted here. Ways of changing the internal appearance, for example, including glass roof openings, and creating a more urban character need to be considered.

Improving the links from car parks or bus and train stations so that transport hubs are more integral to the centre itself could also help this process by making each experience seamless from one to another. Too often linkages are dark and narrow, unappealing and unclear. With the design of car parks starting to improve, it is necessary to start to think of ways to add further value and quality to them and increase associated services, like car servicing, valeting, MOT checks or shop mobility assistance. Office of the Deputy Prime Minister (ODPM) research ${ }^{1}$ suggests that transport improvements will help release development areas by opening up sites. In theory good transport links will increase a development's sustainability because it is easily accessible. The propensity for this, however, will be limited. This should work for the Thames Gateway when that scheme pushes forward as there is available brownfield land and a real desire to improve transport connections. It is less applicable to somewhere like Barnsley. Fulham Broadway is only one of a few completed schemes where this has been done successfully, incorporating good-quality retail above the station with a good mix around the periphery.

In addition, these centres are very inward focused. Rather than simply looking for new retail tenants or taking advantage of flexible units to alter their size, shopping centres should look at alternative development opportunities. A natural extension would be to incorporate leisure into the building and keep the centre open longer. There is no reason why bars, restaurants, cinemas or bingo cannot exist in another zone within the scheme. Traditionally, these uses have been separated from retail and situated in other parts of the town, but with shopping centres often being the town focus, why not develop them further? Breaking down the centre by integrating these alternative uses could help change both the external and internal feeling of the centre.

In addition, the social side of shopping centres can be exploited and banks, dentists, walk-in medical centres and the like incorporated. These are, after all, purely extensions of what many diverse retailers are trying to incorporate into their offer anyway.

On a secondary layer there is ample scope for the insertion of hotels, residential or office elements into appropriate centres. Investment may have driven the idea of single use but research by agents FPD Savills in October $2003^{2}$ has shown better return on 


\section{Space management}

\section{Responding to neighbouring buildings}

mixed use so eyes are now opening to possible change. All of these additional uses would help to increase the flow of people through the centre and keep it open longer. Potsdam Platz in Berlin, for example, successfully incorporates mall-type retail alongside a supermarket and residential, office and cultural offers. These malltype centres, because they are broken down into more easily manageable pieces, provide more flexibility and adaptability.

On the next level is the management of the space within the centre, already briefly raised. Historically they feel like stale, busy internal spaces. There is the opportunity to develop secondary spaces that break out into external areas. This has been done well in Budapest where one of the main centres allows one to go out onto the roof, incorporates a health club that breaks out onto external courtyards and features a busy central space with multiscreened activity. Linked to the transport hub, it also features offices and hotel use that can be accessed from the different spaces both internally and externally. By reconsidering the shape of spaces and use of materials and by altering the roof structure, it is possible to start creating areas that appear to be part of the environment rather than contrived and heavily themed. These additional links or routes help integrate other uses.

To improve the environment that surrounds the centres, the key to success is how they work with their neighbours. They still tend to be too introverted when activity around the edges could enhance what is happening in the rest of the street scene (Figure 3). New entrances may need to be formed or offers moved around to regenerate bigger areas of the city (Figure 4). Constant review of how shopping centres are managed and run is needed, due to the ever-changing fabric around the centre.

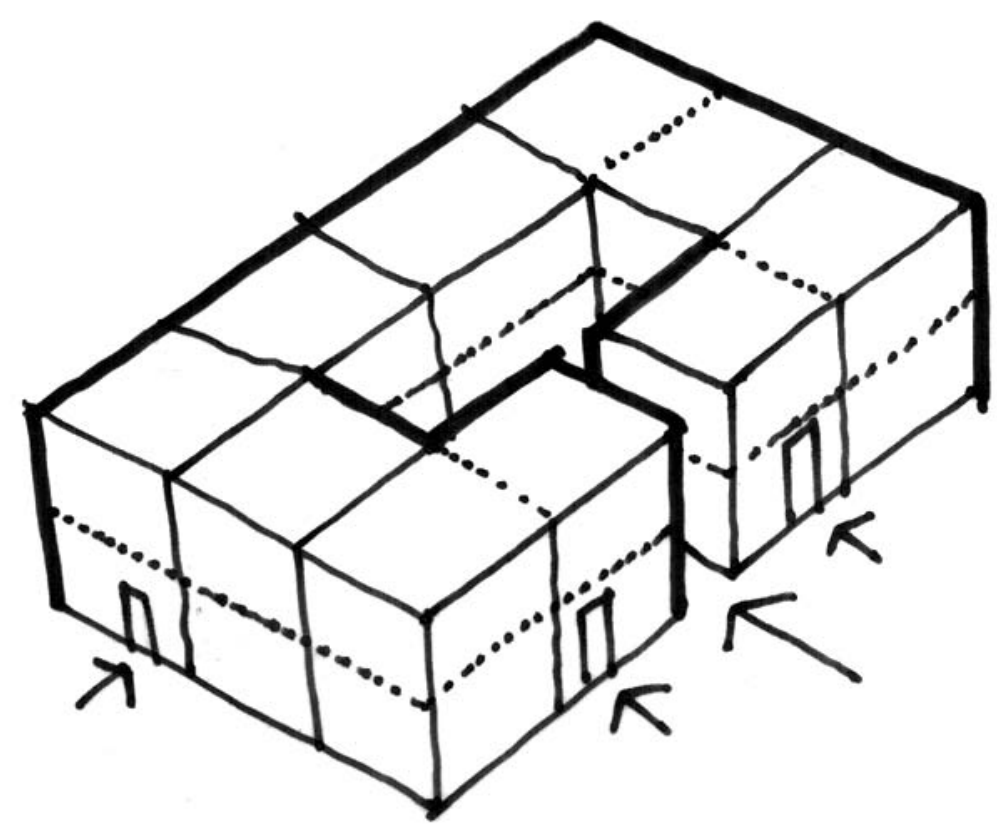

Figure 3: Introverted scheme 


\section{Working together}

\section{Successful examples}

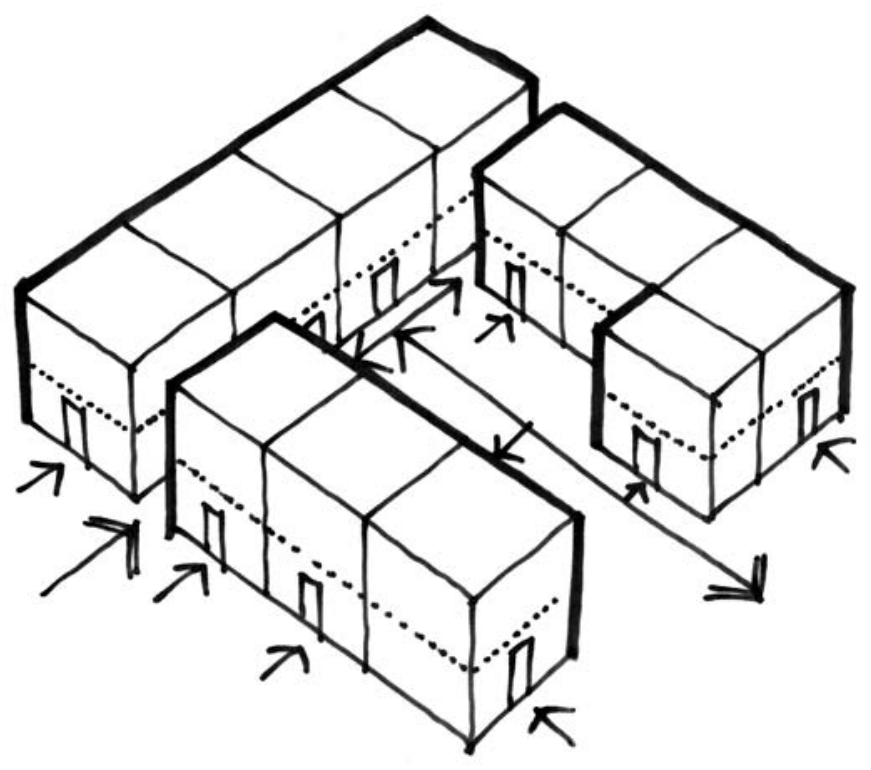

Figure 4: Integrated mixed use

\section{SOCIAL RESPONSIBILITY}

Streets are too often full of disparate retailers and coffee bars. Market forces are driving who takes up vacant units, when with a little thought as to who and what goes where, a far more interesting and stimulating environment could be created. Everyone seems to be on their own, doing their own thing rather than working to a strategy that ensures surrounding land and uses are laid out to the benefit of all. It may be a more challenging route, but housing associations have been getting together for years with the local community to discuss their needs for facilities and spaces. Why cannot landowners, planners or groups of retailers do likewise to improve the space and adjust the balance of uses? Planners, particularly, need to take a more active role and look at compulsory purchase orders.

In a number of street situations throughout the UK, such as Bridlesmith Gate and Lace Market in Nottingham and St Christopher's Place in London, there are examples of groups who have got together to manage their street and build up their own identity. This has followed through from landscaping to the street Christmas decorations, where they have adopted shopping centre principles and put on different themed events to create a unique atmosphere. Within this they consider the opportunities of both horizontal and vertical integration. They allow certain kiosks and street furniture out on the street; in upper-level units or units accessed from alleyways off the main route are snack bars, secondary retailers and offices, which add character and feel but are unable to afford the prime rents. This is a semi-controlled environment, managed by people all with vested interests, although still in the public realm. 


\section{BIDS}

The London initiative

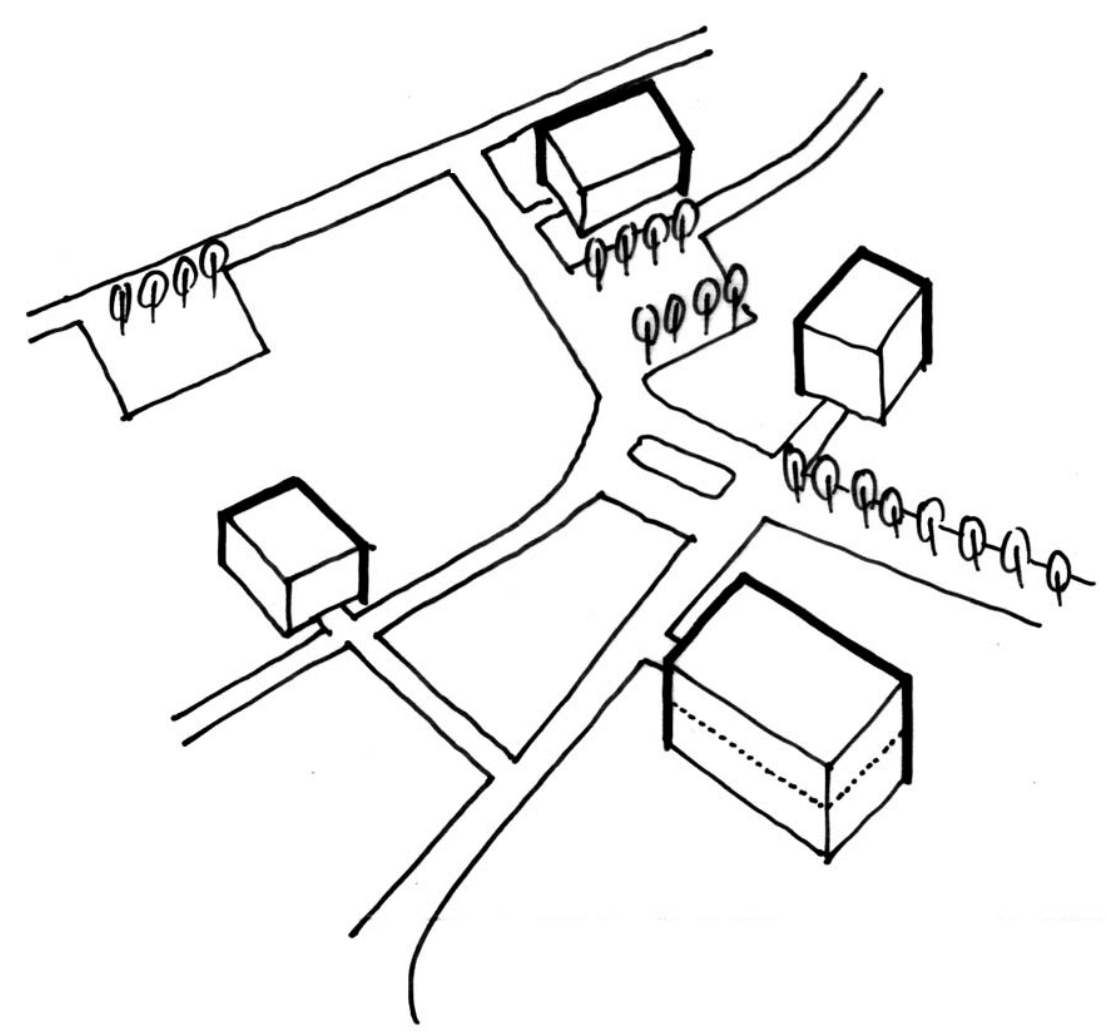

Figure 5: Isolated urban centres

Such street situations are like precursors to the business improvement districts (BIDs) but on a smaller scale. The new community-driven BIDs are more ambitious, along the lines of the successful improvement of Miami in the USA, and bring cities back to life because they are about looking at the district or area rather than an isolated block (Figure 5). BIDs can work because they are about understanding and managing what the community has already got and how best to augment and improve it. It is about appreciating the needs of the street, be that waste management, security or transport issues, and establishing an identity (Figure 6). Urban regeneration depends on business success, consulting businesses at an early stage of regeneration programmes and building in business needs. As Jacquie Reilly, project director at the Association for Town Centre Management, says: 'It's about added value, not what the council already delivers. It is taking things a step further, in partnership, to achieve a common goal - recognising that the public realm equals the trading environment, and vice versa. ${ }^{3}$

A similar initiative, led by major landowners including Land Securities, has been ongoing in Oxford, Regent and Bond Streets where HOK has been appointed to come up with a unitary development plan for the area. In this day and age one can find the same retailers and offers all over the country and there is less reason to want or need to go to London. It is no longer the exclusive retail destination it once was. In addition, some of these 


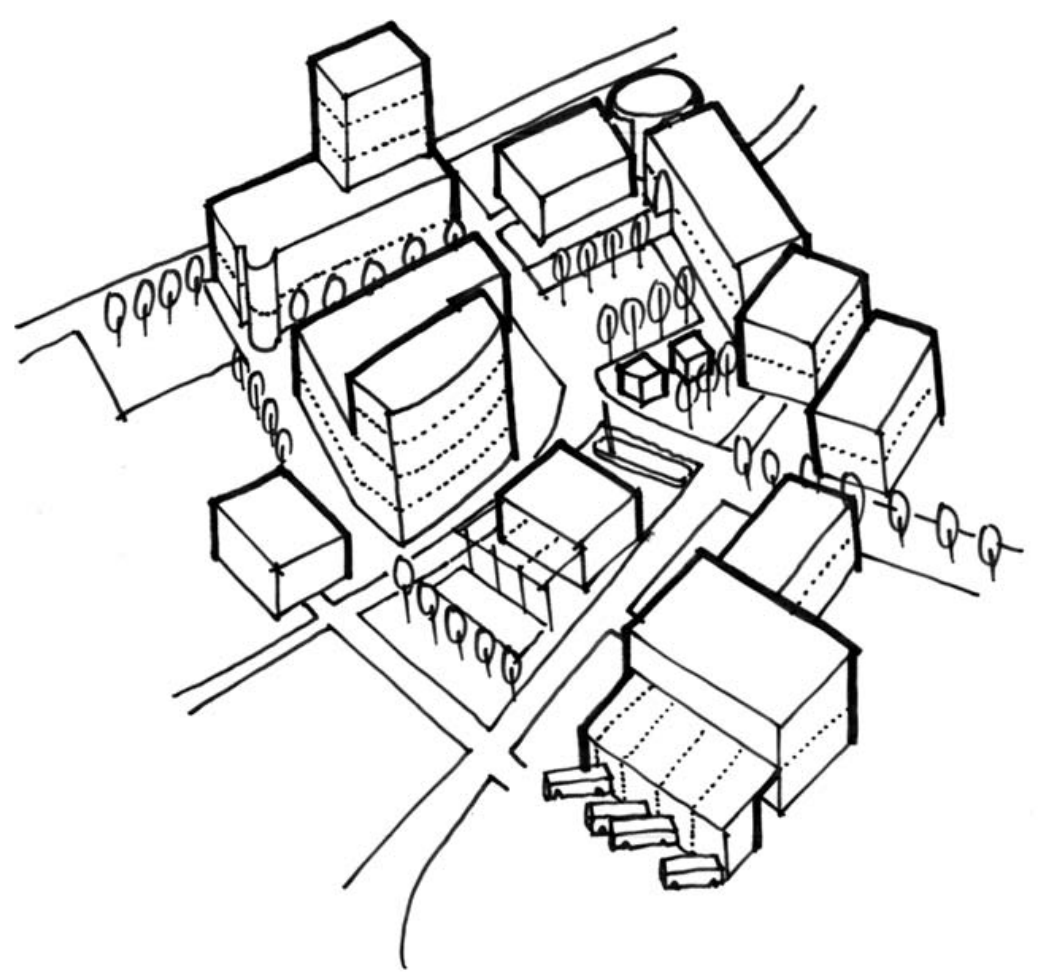

Figure 6: Integrated centres - Connected by clear routes and public spaces supported with transport infrastructure

The social perspective new developments, like the Bullring in Birmingham, have a better quality of street and environment. These top London streets have realised from a business perspective the need to create the right environment to retain custom and indeed prevent the buying public going elsewhere where the overall shopping experience is more pleasant. The problem that London particularly has, despite a concerted effort to improve the situation, is there are so many interested parties the ideas have to go through and be approved by that actual implementation is a drawn-out and difficult process.

The dilemma is that towns and cities develop over hundreds of years. Planners will look at what is best in longevity terms, and would rather leave sites empty than allow short-term development fixes to be built that do not enhance the overall area. Many developers understandably look more in the short term, searching for schemes with the biggest value that will generate the best returns, but this does not necessarily provide the ideal social solution. Unless thinking starts coming more from a social and cultural perspective, there is a danger of creating ghettos rather than communities.

\section{COMMUNITIES WITHIN COMMUNITIES}

Countries, even towns, are made up of different cultures and aspirational values and, with these constantly evolving, it seems 


\section{Insular communities}

\section{The 'OUTRetail' approach}

\section{Social drivers}

Balancing act unlikely that people will ever live in the fully integrated, multi-level, multi-layered cities dreamed up in movies like Flash Gordon or Charlie Chaplin's Modern Times.

A more common 21st-century development is communities within communities, like the Belgrave Road area in Leicester. The area has integrated facilities and is a self-sufficient environment financially, culturally and socially. But for cities to develop to their full potential cross-fertilisation must be encouraged. Residents of these insular communities need to interact with those in other areas and vice versa. How can this be achieved? How can different enclaves be encouraged to overlap socially and culturally? They need a reason to traverse boundaries.

Mixed-use development is too often associated with tight, compact areas within the city centre, when it is far better to consider it under an almost 'out-of-town-retail' approach. It is still mixed use, but developed over a much bigger area, and this is where the failures lie. It is not necessarily about as much or as many types as one can cram into one building or site.

Unless sites are of the scale of, say, Cardiff or the Thames Gateway, there is not going to be a mass of successful mixed-use developments. Schemes will always end up with token retail, token bars and restaurants; they just are not of sufficient scale to create the longevity of use and instead become disassociated blocks. In order to give added value, although each development unit may work in its own right, they need to operate as a coherent whole.

\section{CONCLUSION}

The way in which too many regeneration schemes are approached is wrong; it needs to be turned on its head. Redevelopment should be driven by an area's social make-up. It should not be assumed that if a scheme is a mix of uses and is fully let that it regenerates the community. The Mailbox in Birmingham, for example, has received many awards and accolades, but does it create real community or interaction? Does it provide the perfect retail, leisure, office and residential-type environments or are each of the activities compromised to create the 'right' mix? The waterside leisure provision is the most successful element but is remote from the rest of the scheme. Its success is driven by the water location and the strong links to the other leisure areas and is not particularly aided by the other uses.

Should mixed-use schemes be all things to all men? The simple answer is no. There is a danger of creating pockets of mixed-use schemes rather than regenerating areas through mixed use. If every plot is seen as mixed use in its generic form, although architecturally each may look different, this will see repetitious, soulless blocks that may work well within themselves but do not achieve regenerative and integration objectives.

There has to be a balance. A balance between building new developments and asset managing existing centres. A balance in the 
percentage of each offer included across developments. One end of a street might need more retail, while another may benefit from more leisure. It is necessary to look holistically at urban town strategies and not take a too over-simplistic view of mixed-use schemes.

The key issues that need to be considered are:

The key issues

- fully engaging all stakeholders and the community in depth from the outset

- cooperation: an integrated and comprehensive plan is vital for a town centre, part of which is seeking to ensure all schemes are complementary in terms of tenants, positioning and markets

- delivering developments in a sustainable way both environmentally and economically

- the recognition that design quality and quality spaces are essential ingredients for the creation of urban spaces that inform the architecture around them

- impact: establishing the relevant critical mass in terms of scale, format and location

- permeability: the creation of effective routes through and around the development

- sympathy to the urban grain.

Communities already exist. It is about creating opportunities that encourage them to mix, develop and grow.

\section{References}

1. Office of the Deputy Prime Minister (2002) 'Mixed use development, practice and potential', s. 6.3, available at www.odpm.gov.uk.

2. See www.fpdsavills.co.uk.

3. Reilly, J., speaking at the Association of Town Centre Management autumn conference, 2003. 